\title{
Structural and Magnetic Properties of Iron Oxide Nanoparticles in Shells of Hollow Microcapsules Designed for Biomedical Applications
}

\author{
I. S. Lyubutin, ${ }^{1}$ S. S. Starchikov, ${ }^{1, *}$ Chun-Rong Lin, ${ }^{2, \#}$ N. E. Gervits, ${ }^{1}$ N. Yu. Korotkov, ${ }^{1}$ T. V. Bukreeva ${ }^{1,3}$
}

\footnotetext{
1 Shubnikov Institute of Crystallography, Russian Academy of Sciences, Moscow 119333, Russia

2 Department of Applied Physics, National Pingtung University, Pingtung County 90003, Taiwan

3 National Research Center "Kurchatov Institute“, pl. Akademika Kurchatova 1, Moscow 123182, Russia

* Corresponding author's e-mail address: sergey.postbox@gmail.com

\# Corresponding author's e-mail address: crlinspin@gmail.com
}

RECEIVED: September 12, $2015 *$ ACCEPTED: October 13, 2015

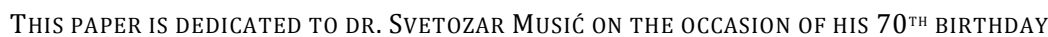

\begin{abstract}
The functional hollow biodegradable microcapsules modified with the maghemite $\gamma-\mathrm{Fe}_{2} \mathrm{O}_{3}$ nanoparticles and the hollow spherical $\mathrm{CoFe}_{2} \mathrm{O}_{4} / \mathrm{SiO}_{2}$ nanocomposites were synthesized. Mössbauer spectroscopy data reveal that the main part maghemite nanoparticles have evident superparamagnetic behavior which is retained up to room temperature. This allows directing the microcapsules by an external magnetic field, which is very important for the problem of target drug delivery. On the other hand, the hollow spherical $\mathrm{CoFe}_{2} \mathrm{O}_{4} / \mathrm{SiO}_{2}$ nanocomposites with the small size particles do not show superparamagnetic behavior, but transit from magnetic to paramagnetic state by jump-like magnetic transition of the first order. This effect is a specific property of the magnetic nanoparticles isolated by an inert material. The method of synthesis can be modified with various bioligands on the silane surface, and such materials can have great prospects for use in diagnostics and bio-separation.
\end{abstract}

Keywords: nanocomposites, Mössbauer spectroscopy, core-shell spheres, maghemite, cobalt-ferrite, size-dependent magnetic properties, firstorder magnetic transition.

\section{INTRODUCTION}

$\mathbf{M}$ AGNETIC nanoparticles (MNP) of iron oxides having unique properties are very promising in many applications, in particular, their use in biology and medicine is of great interest. Targeted drug delivery ${ }^{[1]}$ and theranostics, ${ }^{[2]}$ hyperthermia treatment, ${ }^{[3]}$ contrast media in magnetic resonance imaging, ${ }^{[4]}$ immunoassays, ${ }^{[5]}$ separation and manipulation of biochemical products ${ }^{[6]}$ are the main fields of investigations. The possibility to tune the magnetic properties of iron oxides nanoparticles $\left(\mathrm{Fe}_{3} \mathrm{O}_{4}, \alpha-\mathrm{Fe}_{2} \mathrm{O}_{3}, \gamma-\mathrm{Fe}_{2} \mathrm{O}_{3}, \mathrm{CoFe}_{2} \mathrm{O}_{4}\right)$ by the specific methods of synthesis is very important, and this is the key factor of practical applications of these materials.

For applications in the field of targeted drug delivery, iron oxides MNPs should be non-toxic, chemical stable, biocompatible with cells and tissues of body. MNPs are often used to control and deliver the biodegradable polymeric microcapsules with drug to the cancer tumor. In order to manipulate the microcapsule, MNPs must be able to be controlled by magnetic field and not aggregate after releasing the drug. This is possible if MNPs show the superparamagnetic behavior. The superparamagnetic MNPs reveal zero value of coercitivity and can have high value of saturation magnetization. This allows MNPs to reply on the external magnetic field and do not aggregate after field is removed. The properties of nanoparticles depend on their morphology, agglomeration, surface structure, interparticle interactions and interaction with environment media. These factors can significantly influence the functional properties of the material. 
In this paper two types of microcapsules modified by $\gamma-\mathrm{Fe}_{2} \mathrm{O}_{3}$ and $\mathrm{CoFe}_{2} \mathrm{O}_{4}$ magnetic nanoparticles were synthesized and investigated. Along with magnetic measurements, XRD, SEM, TEM and Mössbauer spectroscopy were used to characterize the structural and magnetic properties of the nanoparticles.

\section{PREPARATION OF THE SAMPLES}

In the first series, hollow microcapsules with the shell composed of biodegradable polyelectrolytes modified with the $\mathrm{Fe}_{3} \mathrm{O}_{4} / \mathrm{Fe}_{2} \mathrm{O}_{3}$ nanoparticles were fabricated by in situ synthesis. Firstly, the spherical $\mathrm{CaCO}_{3}$ particles with diameter of about $5 \mu \mathrm{m}$ were prepared as the core templates for microcapsules. Polyelectrolyte capsules were fabricated by layer-by-layer deposition technique. ${ }^{[7]}$ To obtain hollow capsules, the $\mathrm{CaCO}_{3}$ core was decomposed by EDTA (trisodium salt of ethylenediamine tetraacetic acid). Then, the in situ synthesis of magnetic nanoparticles in a suspension of polyelectrolyte capsules was performed by chemical condensation of $\mathrm{Fe}^{3+}$ and $\mathrm{Fe}^{2+}$ ions $\left(\mathrm{FeCl}_{3}\right.$ and $\mathrm{FeCl}_{2}$ ) on capsule shells by adding a base (the Elmore method). ${ }^{[8]}$ The details of this process could be find in..$^{[9]}$

In the second series, the methyl methacrylate (MMA) and methacrylic acid (MAA) microspheres were used as a core template to prepare the magnetic core-shell nanocomposites of $\mathrm{CoFe}_{2} \mathrm{O}_{4} / \mathrm{SiO}_{2}$. The $\mathrm{CoFe}_{2} \mathrm{O}_{4} /$ poly(MMA-coMAA) core-shell particles were prepared by adding $\mathrm{FeCl}_{3}$ and $\mathrm{CoCl}_{2}$ into the poly(MMA-co-MAA) latex and stirred for $4 \mathrm{~h}$. Tetraethyl orthosilicate (TEOS) was used to cover these particles and obtain the $\mathrm{SiO}_{2} / \mathrm{CoFe}_{2} \mathrm{O}_{4} /$ poly(MMA-co$\mathrm{MAA}$ ) composite spheres. The hollow spheres with shell consisting of $\mathrm{SiO}_{2} / \mathrm{CoFe}_{2} \mathrm{O}_{4}$ nanocomposites were obtained after annealing of $\mathrm{SiO}_{2} / \mathrm{CoFe}_{2} \mathrm{O}_{4} /$ poly(MMA-co-MAA) spheres in air at temperatures $T_{A}$ between 300 and $900{ }^{\circ} \mathrm{C}$ for $4 \mathrm{~h}$. During the calcination, the core MMA-co-MAA microspheres were dissolved.

\section{EXPERIMENTAL TECHNIQUES}

$\mathrm{X}$-ray diffraction studies of $\mathrm{Fe}_{3} \mathrm{O}_{4} / \mathrm{Fe}_{2} \mathrm{O}_{3}$ nanoparticles were performed on a "Belok" station installed on the synchrotron source from a bending magnet of the storage ring in the National Research Center "Kurchatov Institute" (NRCKI), Moscow, Russia. ${ }^{[10]}$ The wavelength was $\lambda=0.9823 \AA$. The crystal structure and phase purity of the $\mathrm{CoFe}_{2} \mathrm{O}_{4}$ samples were examined by powder X-ray diffraction (XRD) using Mutiflex MF2100, Rigaku Co. Ltd.

The morphology and microstructure of the particles were characterized by scanning (SEM) and high resolution transmission electron microscopy (HRTEM). In case of $\mathrm{Fe}_{3} \mathrm{O}_{4} / \mathrm{Fe}_{2} \mathrm{O}_{3}$ nanoparticles a Tecnai $\mathrm{G}_{2} 30 \mathrm{ST}$ (FEI, US) trans- mission/scanning electron microscope (TEM/STEM) operating at an accelerating voltage of $300 \mathrm{kV}$ was used. ${ }^{[9]}$ Also a Tecnai G2 F20, FEGTEM, Philips Co. Ltd. was used to analyze $\mathrm{SiO}_{2} / \mathrm{CoFe}_{2} \mathrm{O}_{4}$ nanocomposites.

The Mössbauer absorption spectra from ${ }^{57} \mathrm{Fe}$ nuclei were recorded at temperatures between 10 and $295 \mathrm{~K}$ using a standard MS1100Em spectrometer operating in the constant acceleration mode. The gamma-ray source ${ }^{57} \mathrm{Co}(\mathrm{Rh})$ was at room temperature. The closed-cycled helium cryostat was used for the low temperature Mössbauer measurements. ${ }^{[11]}$ Isomer shifts were measured relative to the reference $\alpha$-Fe sample (18- $\mu \mathrm{m}$-thick iron foil annealed in hydrogen) at room temperature. Computer processing of spectra was carried out using Univem MS software.

\section{EXPERIMENTAL RESULTS}

\subsection{Sample Characterization by XRD and Electron Microscopy.}

$\mathrm{X}$-ray diffraction patterns of microcapsules modified by $\mathrm{Fe}_{3} \mathrm{O}_{4} / \mathrm{Fe}_{2} \mathrm{O}_{3}$ nanoparticles and $\mathrm{CoFe}_{2} \mathrm{O}_{4} / \mathrm{SiO}_{2}$ composite recorded after annealed the samples at different temperatures $T_{\mathrm{A}}$ are shown in Figure $1 \mathrm{a}$ and Figure $1 \mathrm{~b}$.

The Rietveld method was used for the crystal structure refinement of iron oxide $\mathrm{Fe}_{3} \mathrm{O}_{4} / \mathrm{Fe}_{2} \mathrm{O}_{3}$ nanoparticles. For the peak interpolation, the symmetric pseudo-Voigt function was applied. The Bragg $R$-factor $R_{\mathrm{Br}}=2.1 \%$ was obtained. All reflections in Figure 1a correspond to the cubic spinel-type structure (sp. gr. $F d \overline{3} m$ ) and the calculated unit cell parameter is $a=8.3545$ (3) $\AA$. Assuming the spherical shape of the particles we estimate the average crystallite size of $D=12(1) \mathrm{nm}$ by Scherrer's formula of the peak broadening. ${ }^{[12]}$ It is difficult to separate magnetite $\mathrm{Fe}_{3} \mathrm{O}_{4}$ and maghemite $y-\mathrm{Fe}_{2} \mathrm{O}_{3}$ phases in XRD pattern because both have a spinel-type crystal structure. In order to verify reliably the iron oxide phase, we carried out Mössbauer spectroscopy measurements which very sensitive for iron valence state $\left(\mathrm{Fe}^{3+}, \mathrm{Fe}^{2+}\right)$.

All peaks in the XRD patterns of $\mathrm{CoFe}_{2} \mathrm{O}_{4} / \mathrm{SiO}_{2}$ nanocomposites (Figure $1 \mathrm{~b}$ ) can be indexed to the $\mathrm{Fd} \overline{3} \mathrm{~m}$ space group in the cubic symmetry related to the spinel structure of cobalt ferrite. ${ }^{[13]}$ The peak of $\mathrm{SiO}_{2}$ should be located at about $2 \theta=24^{\circ}$ but it is not visible due to amorphous state of silica. The calculated unit cell parameter is $a=8.380(1) \AA$ which is closed to nanoscale cobalt ferrites. ${ }^{[13]}$ We calculated an average crystallite size of the coated $\mathrm{CoFe}_{2} \mathrm{O}_{4}$ nanoparticles from the width of (311) peak using Scherrer method. ${ }^{[12]}$ The particle size $d$ is about 2.2 and $10.2 \mathrm{~nm}$ in the samples annealed at $T_{\mathrm{A}}=300$ and $900{ }^{\circ} \mathrm{C}$, respectively.

The SEM, TEM and HRTEM images of polyelectrolyte microcapsules with $\mathrm{Fe}_{3} \mathrm{O}_{4} / \mathrm{Fe}_{2} \mathrm{O}_{3}$ in shells are shown in 

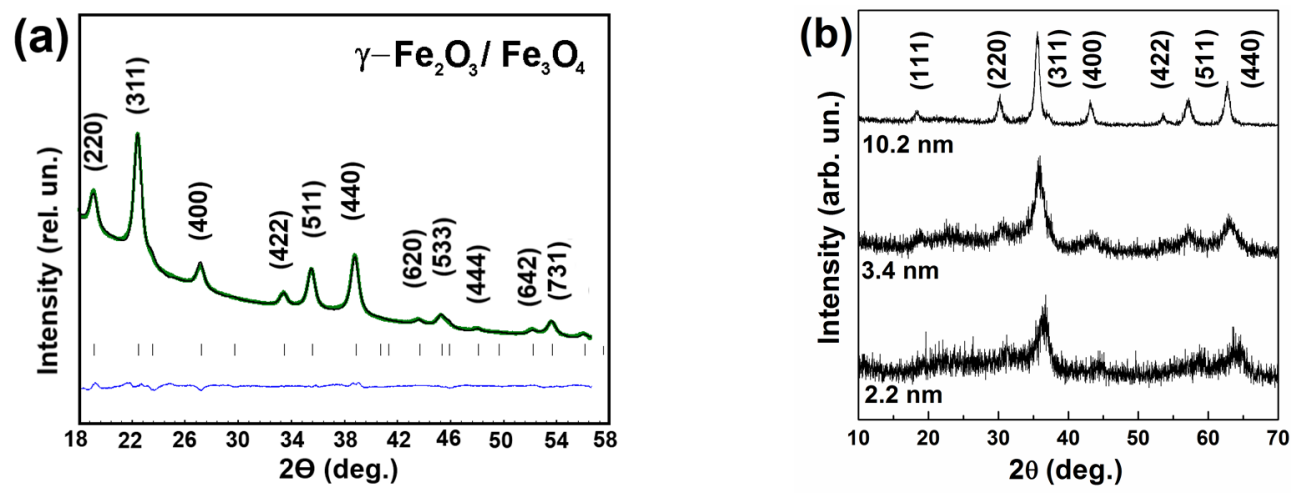

Figure 1. X-ray diffraction patterns of the $\mathrm{Fe}_{3} \mathrm{O}_{4} / \mathrm{Fe}_{2} \mathrm{O}_{3}$ (a) and $\mathrm{CoFe}_{2} \mathrm{O}_{4} / \mathrm{SiO}_{2}$ (b) composites in shells of microcapsules. The reflection indexes correspond to the cubic spinel-type structure (sp. gr. $F d \overline{3} m$ ).

Figure $2 a, b, c$. The microcapsules have uniform spherical shape with diameter of about $6.7 \mu \mathrm{m}$ while the average thickness of the capsule shell is about $0.9 \mu \mathrm{m}$ (Figure 2b). It was established from the HRTEM data that the average size of the $\mathrm{Fe}_{3} \mathrm{O}_{4} / \mathrm{Fe}_{2} \mathrm{O}_{3}$ nanoparticles in shell of the microcapsules varies from 6 to $9 \mathrm{~nm}$ for more than $94 \%$ nanoparticles with an average value of about $7.5 \mathrm{~nm}$ (Figure $2 \mathrm{c}$ ).

The SEM and TEM images of microcapsules consisting of the $\mathrm{CoFe}_{2} \mathrm{O}_{4} / \mathrm{SiO}_{2}$ nanocomposites are shown in Figure $2 \mathrm{~d}, \mathrm{e}, \mathrm{f}$. The capsules have spherical shape and uniform size of about $450 \mathrm{~nm}$ in diameter (Figure 2d,e). The thickness of the shell consisting of $\mathrm{CoFe}_{2} \mathrm{O}_{4} / \mathrm{SiO}_{2}$ is about $40-50 \mathrm{~nm}$ (Figure 2e). As seen in the HRTEM image of Figure $2 \mathrm{f}$, the size of $\mathrm{CoFe}_{2} \mathrm{O}_{4}$ nanoparticles annelid at $900{ }^{\circ} \mathrm{C}$ is about 10 $\mathrm{nm}$, which correlates with estimation of the particle size from the XRD data by the Sherrer method.
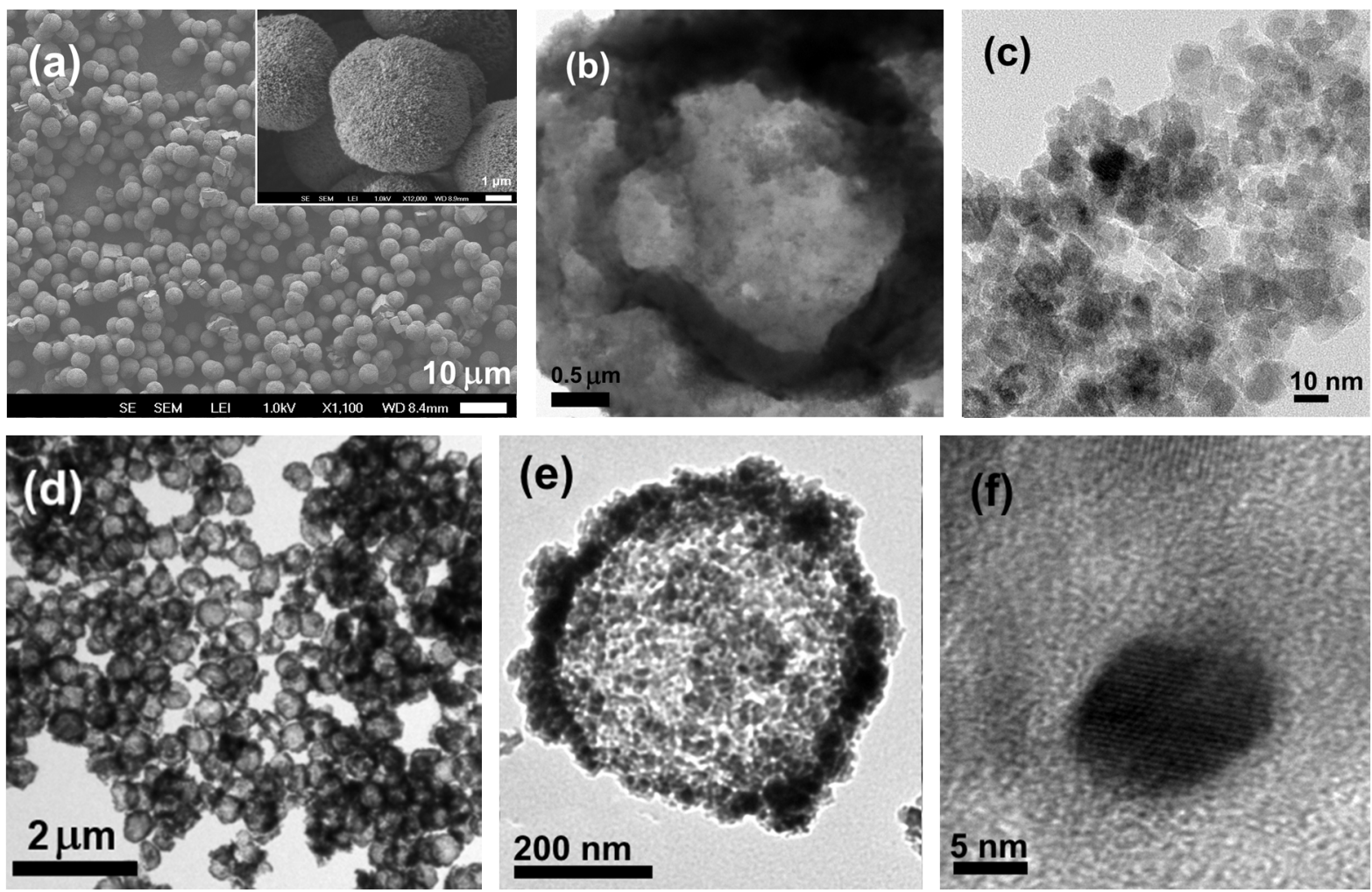

Figure 2. SEM (a) and TEM (b,c) images of the hollow polyelectrolyte microcapsules modified by iron oxides $\mathrm{Fe}_{3} \mathrm{O}_{4} / \mathrm{Fe}_{2} \mathrm{O}_{3}$, and $\operatorname{TEM}(d, e)$ and HRTEM (f) images of the nanocomposite $\mathrm{CoFe}_{2} \mathrm{O}_{4} / \mathrm{SiO}_{2}$ creating the microcapsule shells. 


\subsection{Mössbauer Spectroscopy Measure- ments}

\subsubsection{IRON OXIDES NANOPARTICLES IN SHELLS OF HOLLOW BIODEGRADABLE POLYELECTROLYTES MICROCAPSULES}

The temperature evolution of $\mathrm{Fe}^{57}$-Mossbauer spectra of $\mathrm{Fe}_{3} \mathrm{O}_{4} / \mathrm{Fe}_{2} \mathrm{O}_{3}$ nanoparticles between 10 and $295 \mathrm{~K}$ is showed in Figure3a. Low-temperature spectra indicate that all iron ions are in the magnetically ordered state. These spectra can be fit to two dominating and one small-intensive magnetic components $A, B$, and $C$, respectively (Figure $3 b)$. The hyperfine parameters for $A$ and $B$ components at $10 \mathrm{~K}$ are: isomer shifts $\delta(A)=0.41 \mathrm{~mm} / \mathrm{s}, \delta(B)=0.46 \mathrm{~mm} / \mathrm{s}$, quadrupole shifts $\varepsilon(A)=-0.03, \varepsilon(B)=0.01 \mathrm{~mm} / \mathrm{s}$, and magnetic hyperfine fields $H_{h f}(\mathrm{~A})=50.5 \mathrm{~T}$ and $H_{h f}(\mathrm{~B})=52.6 \mathrm{~T}$. The values of isomer shifts are typical of ferric $\mathrm{Fe}^{3+}$ ions, and no ferrous $\mathrm{Fe}^{2+}$ ions were found in the sample. This indicates that magnetite $\mathrm{Fe}_{3} \mathrm{O}_{4}$ phase is not present in these nanoparticles. Taken into account the XRD data (indicating the spinel structure of these NPs), we have to conclude that the particles have the crystal structure of maghemite $\gamma-\mathrm{Fe}_{2} \mathrm{O}_{3}$. Maghemite and magnetite are iron oxides with the same cubic spinel structure, but their electronic and magnetic properties are different. In the spinel structure, iron ions occupy tetrahedral $(A)$ and octahedral $[B]$ sites, and in the chemical formula of magnetite ferrous ions are located in the octahedral sites $\left(\mathrm{Fe}^{3+}\right)\left[\mathrm{Fe}^{3+} \mathrm{Fe}^{2+}\right] \mathrm{O}_{4}$. The chemical formula of maghemite $\gamma-\mathrm{Fe}_{2} \mathrm{O}_{3}$ can be represented as nonstoichiometric magnetite containing vacancies $\square$ in the octahedral sites (Fe) $\left[\mathrm{Fe}_{5 / 6} \square_{1 / 6}\right]_{2} \mathrm{O}_{4}$. All iron ions in maghemite are ferric.

Two main magnetic components in the Mössbauer spectrum of our NPs correspond to the $\mathrm{Fe}^{3+}$ iron ions in tetrahedral (A) and octahedral [B] sites of maghemite $\gamma-\mathrm{Fe}_{2} \mathrm{O}_{3} \cdot{ }^{[14]}$ The intensity ratio of the (A) and [B] Mössbauer components in the vacant $\gamma-\mathrm{Fe}_{2} \mathrm{O}_{3}$ is expected to be near $1: 1.67$. In our case, the observed $A / B$ ratio in nanoparticles is about 1.65 that is very close to the expected value for maghemite. This is an additional support for the maghemite phase present in the shells of the microcapsules obtained.

The third magnetic component $(\mathrm{C})$ in Figure $3 \mathrm{~b}$ has the isomer shift $\delta(C)=0.44 \mathrm{~mm} / \mathrm{s}, \varepsilon(\mathrm{C})=-0.06 \mathrm{~mm} / \mathrm{s}$, and $\left\langle H_{h f}(\mathrm{C})\right\rangle=47.0 \mathrm{~T}$. These parameters are also should be attributed to the ferric ions. The lines of this component are much broadened, and its relative area is about $15 \%$. Obviously the third component (C) corresponds to iron ions on the surface of the nanoparticles. ${ }^{[9]}$

As temperature increases, at $T>70 \mathrm{~K}$ the paramagnetic doublet component appears in the central part of the spectra (Figure 3a). This indicates that some part of the na-
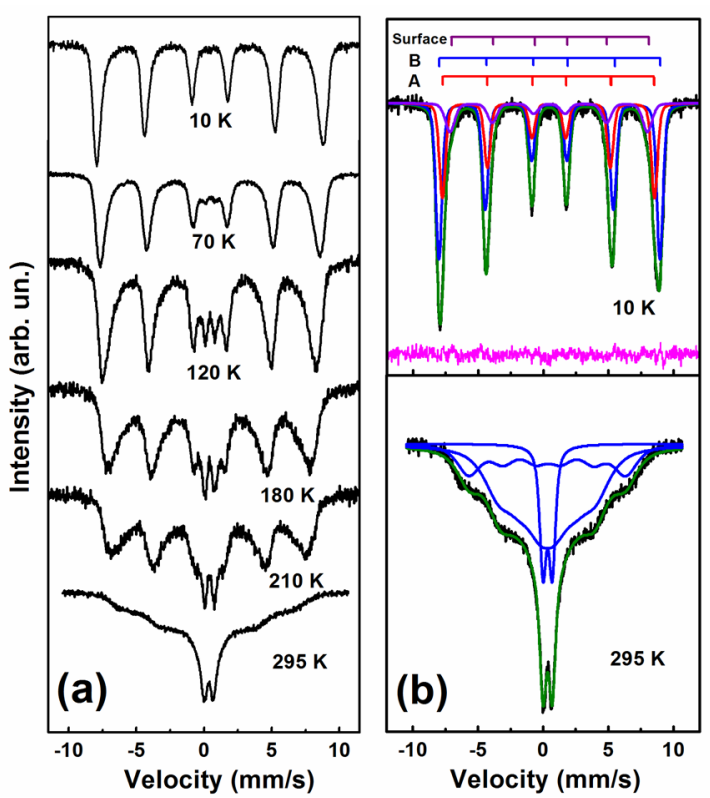

Figure 3. The $\mathrm{Fe}^{57}$-Mössbauer spectra of the iron oxide $\gamma-\mathrm{Fe}_{2} \mathrm{O}_{3}$ nanoparticles in shells of microcapsules recorded at temperatures between 10 and $295 \mathrm{~K}$.

noparticles undergoes the transition from magnetically ordered to paramagnetic state. The isomer shift of the doublet is $\delta=0.43(1) \mathrm{mm} / \mathrm{s}$, the quadrupole splitting $\Delta=$ 0.79 (1) $\mathrm{mm} / \mathrm{s}$, and the half-line width $\Gamma=0.81(2) \mathrm{mm} / \mathrm{s}$. These values are the typical characteristics of the high spin $\mathrm{Fe}^{3+}$ ions in maghemite. ${ }^{[14-16]}$ The area of the doublet increases with increasing temperature. It should be noted that we did not observed remarkable transformations of the spectra shape at temperatures where the Verwey transition occurs in magnetite $\mathrm{Fe}_{3} \mathrm{O}_{4}$ (around $120 \mathrm{~K}$ ). This additionally confirms an absence of magnetite in the sample.

The line broadening increases as temperature rises, and at room temperature the spectrum consists of the overlapping broad magnetic component and paramagnetic doublet (Figure 3b). The parameters of the doublet $\delta=$ $0.34(1) \mathrm{mm} / \mathrm{s}, \Delta=0.70(1) \mathrm{mm} / \mathrm{s}$ and $\Gamma=0.61(1) \mathrm{mm} / \mathrm{s}$ are closed to nano-maghemite. ${ }^{[14,15]}$ Such behavior of the spectra is the signature of superparamagnetic relaxation of the iron magnetic moments. Thus, at room temperature the $\gamma$ $\mathrm{Fe}_{2} \mathrm{O}_{3}$ nanoparticles reveal superparamagnetism.

\subsubsection{HOLLOW MICROCAPSULES MADE OF $\mathrm{CoFe}_{2} \mathrm{O}_{4} / \mathrm{SiO}_{2}$ NANOCOMPOSITES}

The $\mathrm{Fe}^{57}$-Mossbauer spectra of $\mathrm{CoFe}_{2} \mathrm{O}_{4} / \mathrm{SiO}_{2}$ nanocomposites at temperatures between 10 and $295 \mathrm{~K}$ are shown in Figure 4. Well resolved six-line magnetic pattern is clearly seen at low temperatures. However, the evolution of the spectra is different for the samples with different size. The 
transition from the magnetically ordered state to a paramagnetic state occurs at about $T>60 \mathrm{~K}$ in the samples with the particle size of (2.2-3.4) nm (Figure 4a), whereas a magnetic order persists for all iron ions in the $10.2 \mathrm{~nm}$ sample even above room temperature (Figure $4 \mathrm{~b}$ ).

At $10 \mathrm{~K}$, the spectra of $10.2 \mathrm{~nm}$ sample can be fit to several magnetic components corresponding to nonequivalent iron ion states in cubic spinel structure of $\mathrm{CoFe}_{2} \mathrm{O}_{4}$. The isomer shift values $\delta$ in all components are about $0.37-$ $0.49 \mathrm{~mm} / \mathrm{s}$, which are typical for $\mathrm{Fe}^{3+}$ ions. The ferrous ions $\mathrm{Fe}^{2+}$ were not found. Thus, the cobalt ions should be bivalent $\mathrm{Co}^{2+}$, and the general formula of cobalt ferrite can be given as: $\left(\mathrm{CO}^{2+}{ }_{x} \mathrm{Fe}^{3+}{ }_{1-x}\right)\left[\mathrm{Co}^{2+}{ }_{1-x} \mathrm{Fe}^{3+}{ }_{1+x}\right] \mathrm{O}_{4}$.

Several nonequivalent iron sites in $\mathrm{CoFe}_{2} \mathrm{O}_{4}$ appear due to different number of $\mathrm{Fe}$ and $\mathrm{Co}$ neighbors in the nearest sublattice. The isomer shift $\delta$ and magnetic hyperfine field $H_{h f}$ values for iron ions in A-site are less than in B-site due to stronger covalence of the Fe-O bonds in A-site. Thus, we can assign the Mössbauer components to $\mathrm{Fe}^{3+}$ ions in (A)- and [B] sites, and the fraction of $\mathrm{Fe}^{3+}$ ions in tetrahedral and octahedral sublattices can be determined from the areas of the corresponding components. Thus, we found the cation distribution in the $10.2 \mathrm{~nm}$ sample in the form: $\left(\mathrm{Co}^{2+}{ }_{0.33} \mathrm{Fe}^{3+}{ }_{0.67}\right)\left[\mathrm{CO}^{2+}{ }_{0.67} \mathrm{Fe}^{3+}{ }_{1.33}\right] \mathrm{O}_{4}$. The inversion degree $\lambda$
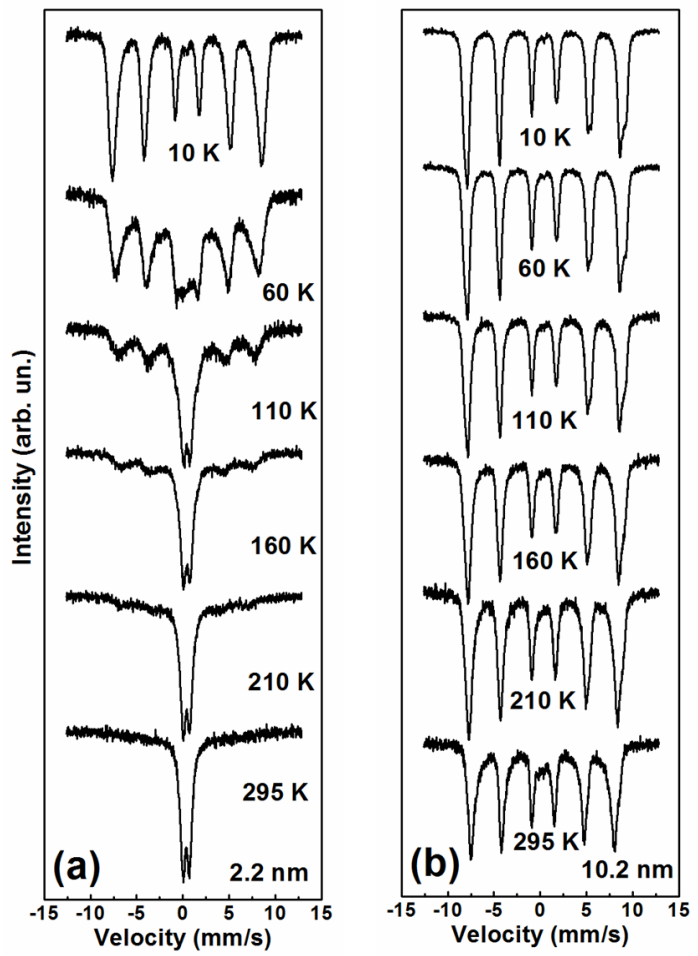

Figure 4. Temperature evolution of the Fe $\mathrm{Fe}^{57}$-Mössbauer spectra between 10 and $295 \mathrm{~K}$ in the $\mathrm{CoFe}_{2} \mathrm{O}_{4} / \mathrm{SiO}_{2}$ samples with the particle size of 2.2 and $10.2 \mathrm{~nm}$ calcinated at 300 and $900^{\circ} \mathrm{C}$, respectively. which is defined as the fraction of (A) sites occupied by trivalent cations, is of $\lambda=0.67(1)$, and this is close to the values obtained in the bulk cobalt ferrite. ${ }^{[18,19]}$

\section{DISCUSSION}

Mössbauer spectroscopy is an accurate method to study the superparamagnetic relaxation phenomenon. The timescale of measurements in Mössbauer spectroscopy is an order of nanoseconds, which is much more less than in DC magnetization measurements and applying of the external magnetic field is not necessary. This allows investigating fast spin relaxation processes in nanoparticles caused by the thermal energy. The time of thermal fluctuation $\tau$ of magnetic moments among the various easy directions of magnetization is given by well-known formula: ${ }^{[20]}$

$$
\tau=\tau_{0} \exp \left(V K / k_{B} T\right)
$$

where $\tau_{0}$ is the material constant $\left(\sim 10^{-9} \mathrm{~s}\right),{ }^{[21]} K$ is the anisotropy constant, $k_{B}$ is the Boltzmann constant, $V$ is the volume of nanoparticles, and $T$ is the temperature. The magnetization is stable below the spin-blocking temperature $T_{b}$, and the thermal equilibrium state of the assembly of uniaxial single-domain nanoparticles can be given in the form:[21]

$$
V K=2.3 k_{B} T_{b},
$$

From the temperature dependence of the area of paramagnetic component we estimated the $T_{b}$ values as $\approx$ 90 and $\approx 250 \mathrm{~K}$ for the $\gamma-\mathrm{Fe}_{2} \mathrm{O}_{3}$ nanoparticles with size of $d$ $\leq 5$ and $6 \mathrm{~nm}$, respectively. Using the values of $V$ and $T_{b}$ obtained in our experiments we estimated the anisotropy constants $K=4 \times 10^{5} \mathrm{erg} / \mathrm{cm}^{3}$ and $7 \times 10^{5} \mathrm{erg} / \mathrm{cm}^{3}$ for the particles with the sizes of 5 and $6 \mathrm{~nm}$, respectively. These data show that the surface anisotropy (which relative contribution to the total anisotropy in $5 \mathrm{~nm}$ particles is higher than in $6 \mathrm{~nm}$ particles) is less than the core particle anisotropy. This can be attributed to coating of the nanoparticles by nonmagnetic polyelectrolyte media.

Contrary to the $\gamma-\mathrm{Fe}_{2} \mathrm{O}_{3}$ nanoparticles in shells of biodegradable polyelectrolytes microcapsules, the $\mathrm{CoFe}_{2} \mathrm{O}_{4}$ particles covered by amorphous silica $\mathrm{SiO}_{2}$ do not reveal superparamagnetic behavior even in very small samples of $(2.2-3.4) \mathrm{nm}$. At temperature increasing from $10 \mathrm{~K}$, the area of magnetic six-linear component starts to decrease at about $T>60 \mathrm{~K}$ due to the appearance of the paramagnetic doublet (Figure 4a), meanwhile, the line width remains unchanged, and the shape of the spectra does not show relaxation broadening typical of superparamagnetism. The average values of the magnetic hyperfine field $H_{\mathrm{hf}}$ also did not change significantly. The magnetic sextet directly 
transits into a paramagnetic doublet without relaxation phenomena typical of superparamagnetic behavior. This indicates that in small particles $(2.2,2.4$ and $3.4 \mathrm{~nm})$, a certain part of magnetic Fe ions transits to the paramagnetic state by the jump-like first order magnetic transition (JMT) without an intermediate relaxation state.

Such a transition was discovered previously in ferrihydrite $\left(\mathrm{Fe}_{5} \mathrm{HO}_{8} \cdot 4 \mathrm{H}_{2} \mathrm{O}\right)$ nanoparticles with the size of $2 \mathrm{~nm}$; located in the copolymer pores, ${ }^{[22]}$ and in nanocomposites of $\alpha-\mathrm{Fe}_{2} \mathrm{O}_{3} / \mathrm{SiO}_{2}$, in which the 2-4 nm size nanoparticles of hematite $\alpha-\mathrm{Fe}_{2} \mathrm{O}_{3}$ were located in the amorphous silica channels. ${ }^{[23]}$ In both cases, the magnetic nanoparticles were isolated by inert material, which is similar to our $\mathrm{CoFe}_{2} \mathrm{O}_{4} / \mathrm{SiO}_{2}$ samples.

Thermodynamical analysis indicated ${ }^{[22]}$ that such a transition can be initiated by internal pressure created in the surface layer of the particle. The temperature of the transition depends on many parameters such as the particle size, degree of isolation of the particles from each other, the particle aggregations in nanoclusters, and intercluster interaction. The interaction between the surface $\mathrm{Fe}^{3+}$ ions and the wall of the coating material can influences the surface tension and pressure, thus changing the value of the magnetic transition temperature. Spread of values of the transition temperature can also be explained by the intercluster interactions. ${ }^{[23]}$ The covered material can induce pressure on the nanoparticles and this effect can shift the transition temperature. Considering the size distribution of $\mathrm{CoFe}_{2} \mathrm{O}_{4}$ nanoparticles one can expect a gradual transition from magnetically ordered to paramagnetic state.

\section{CONCLUSION}

The functional hollow biodegradable microcapsules modified with the iron oxide nanoparticles in shells and the hollow spherical $\mathrm{CoFe}_{2} \mathrm{O}_{4} / \mathrm{SiO}_{2}$ nanocomposites were synthesized.

Mössbauer spectroscopy data revealed that the iron oxide nanoparticles in shells of the capsules have the crystal structure of maghemite $\mathrm{\gamma}-\mathrm{Fe}_{2} \mathrm{O}_{3}$. The most important data reveals that approximately $80 \%$ of all maghemite nanoparticles with the size of 7-9 $\mathrm{nm}$ have evident superparamagnetic behavior which is retained up to room temperature due to slow spin relaxation. This allows directing the microcapsules to a place determined by an external magnetic field, which is very important for the problem of target drug delivery. Mild conditions in the synthesis of magnetic nanoparticles incorporated in the microcapsules may enable encapsulating bioactive substances without loss of its biological activity.

On the other hand, the hollow spherical $\mathrm{CoFe}_{2} \mathrm{O}_{4} / \mathrm{SiO}_{2}$ nanocomposites with the small size of the
$\mathrm{CoFe}_{2} \mathrm{O}_{4}$ particles $(2.2,2.4$ and $3.4 \mathrm{~nm})$ do not show superparamagnetic behavior, but transit from magnetic to paramagnetic state by jump-like magnetic transition of the first order. This effect is a specific property of the magnetic nanoparticles isolated by an inert material. Such a transition is related to the surface effects, and in particular, can be initiated by internal pressure creating in a surface layer of the particle. The method of synthesis can be modified with various bio-ligands on the silane surface in order to covalently attach the specific bioligands to the surfaces of the hollow magnetic spheres. Such materials can have great prospects for use in diagnostics and bio-separation.

Acknowledgements. Support by the Russian Scientific Foundation (Project \#14-12-00848) is acknowledged.

\section{REFERENCES}

[1] H.-S. Cho, Z. Dong, G. M. Pauletti, J. Zhang, H. Xu, H. Gu, L. Wang, R. C. Ewing, C. Huth, F. Wang, D. Shi, ACS Nano 2010, 4(9), 5398.

[2] Z. Li, J. C. Barnes, A. Bosoy, J. F. Stoddart, J. I. Zink, Chem. Soc. Rev. 2012, 41(7), 2590.

[3] S. Mornet, S. Vasseur, F. Grasset, E. Duguet, J Mater Chem 2004, 14(14), 2161.

[4] F. Hu, K. W. MacRenaris, E. A. Waters, E. A. SchultzSikma, A. L. Eckermann, T. J. Meade, Chem. Commun. 2010, 46(1), 73.

[5] H. Nakayama, A. Arakaki, K. Maruyama, H. Takeyama, T. Matsunaga, Biotechnol. Bioeng. 2003, 84(1), 96.

[6] J. Ugelstad, A. Berge, T. Ellingsen, R. Schmid, T.-N. Nilsen, P. C. Mørk, P. Stenstad, E. Hornes, $\varnothing$. Olsvik, Prog. Polym. Sci. 1992, 17(1), 87.

[7] G. B. Sukhorukov, E. Donath, H. Lichtenfeld, E. Knippel, M. Knippel, A. Budde, H. Möhwald, Colloids Surf. Physicochem. Eng. Asp. 1998, 137(1-3), 253.

[8] W. C. Elmore, Phys. Rev. 1938, 54(4), 309.

[9] I. S. Lyubutin, S. S. Starchikov, T. V. Bukreeva, I. A. Lysenko, S. N. Sulyanov, N. Y. Korotkov, S. S. Rumyantseva, I. V. Marchenko, K. O. Funtov, A. L. Vasiliev, Mater. Sci. Eng. C 2014, 45, 225.

[10] D. M. Kheiker, M. V. Kovalchuk, Y. N. Shilin, V. A. Shishkov, S. N. Sulyanov, P. V. DorovatovskiĬ, A. A. Rusakov, Crystallogr. Rep. 2007, 52(2), 358.

[11] P. G. Naumov, I. S. Lyubutin, K. V. Frolov, E. I. Demikhov, Instrum. Exp. Tech. 2010, 53(5), 770.

[12] J. I. Langford, A. J. C. Wilson, J. Appl. Crystallogr. 1978, 11(2), 102.

[13] L. Kumar, P. Kumar, A. Narayan, M. Kar, Int. Nano Lett. 2013, 3(1), 1.

[14] A. G. Roca, J. F. Marco, M. del P. Morales, C. J. Serna, J. Phys. Chem. C 2007, 111(50), 18577. 
[15] K. Závěta, A. Lančok, M. Maryško, E. Pollert, D. Horák, Czechoslov. J. Phys. 2006, 56(3), E83.

[16] G. M. Da Costa, E. De Grave, L. H. Bowen, R. E. Vandenberghe, P. M. A. De Bakker, Clays Clay Miner. 1994, 42(5), 628.

[17] G. A. Sawatzky, F. Van Der Woude, A. H. Morrish, Phys. Rev. 1969, 187(2), 747.

[18] T. A. S. Ferreira, J. C. Waerenborgh, M. H. R. M. Mendonça, M. R. Nunes, F. M. Costa, Solid State Sci. 2003, 5(2), 383.

[19] G. A. Sawatzky, F. V. D. Woude, A. H. Morrish, J. Appl. Phys. 1968, 39(2), 1204.
[20] L. Neel, Ann. Geophys. 1949, 5, 99.

[21] B. D. Cullity, Introduction to magnetic materials. Addison-Wesley Pub. Co., 1972.

[22] I. P. Suzdalev, V. N. Buravtsev, V. K. Imshennik, Y. V. Maksimov, V. V. Matveev, S. V. Novichikhin, A. X. Trautwein, H. Winkler, Z. Für Phys. At. Mol. Clust. 2014, 37(1), 55.

[23] I. P. Suzdalev, Y. V. Maksimov, V. K. Imshennik, S. V. Novichikhin, M. I. Ivanovskaya, D. A. Kotikov, V. V. Pan'kov, Y. Lyubina, Nanotechnologies Russ. 2010, 5(11-12), 817. 